\title{
Simultaneous Dual Hepatic Vascular Embolization (DHVE) for Massive Hepatectomy
}

\author{
Koichiro Haruki, MD, $\mathrm{PhD}^{1}$ (D) , Kenei Furukawa, MD, $\mathrm{PhD}^{1}$, Hirokazu Ashida, $\mathrm{MD}, \mathrm{PhD}^{2}$, \\ Yoshihiro Shirai, MD, $\mathbf{P h D}^{1}$, Shinji Onda, $\mathrm{MD}, \mathrm{PhD}^{1}$, Masashi Tsunematsu, $\mathrm{MD}, \mathrm{PhD}^{1}$, and \\ Toru Ikegami, MD, $\mathbf{P h D}^{1}$ \\ ${ }^{1}$ Division of Hepatobiliary and Pancreatic Surgery, Department of Surgery, The Jikei University School of Medicine, \\ Tokyo, Japan; ${ }^{2}$ Department of Radiology, The Jikei University School of Medicine, Tokyo, Japan
}

\begin{abstract}
Background. Simultaneous dual hepatic vein embolization (DHVE) has been proposed for safe right-side massive hepatectomy, (Kobayashi et al. in Surgery 167:917-923, 2020, Heil J, Schadde E. in Langenbecks Arch Surg 2020, Narita et al. in Ann Surg 256:e7-8, 2012) and has demonstrated comparable results to associating liver partition and portal vein ligation for staged hepatectomy (ALPPS) (Chan et al. in Transl Gastroenterol Hepatol 5:37, 2020) in terms of liver hypertrophy. In this video, we describe our DHVE techniques to perform a safe right trisectionectomy.

Methods. A 40-year-old man with unresectable intrahepatic cholangiocarcinoma with multiple intrahepatic metastases and vena cava invasion received 20 cycles of gemcitabine plus cisplatin, resulting in remarkable shrinkage of the tumor. Conversion surgery was planned to achieve no evidence of disease status. The future liver remnant (FLR) after right trisectionectomy was $363 \mathrm{ml}(29.6 \%$ of the whole liver) and simultaneous DHVE was performed. The right portal vein embolization was performed via a transhepatic approach, while the right and middle hepatic veins were accessed via a transjugular approach and self-expandable mesh devices were deployed. Remarkable atrophy of the
\end{abstract}

Supplementary Information The online version contains supplementary material available at https://doi.org/10.1245/s10434021-10433-z.

(C) Society of Surgical Oncology 2021

First Received: 17 March 2021

Accepted: 24 June 2021;

Published Online: 7 July 2021

K. Haruki, MD, PhD

e-mail: haruki@jikei.ac.jp right lobe and hypertrophy of the left lobe was observed 2 weeks after the procedure. Volumetry showed the FLR increased to $485 \mathrm{ml}$ (40.2\% of the whole liver). Three weeks after DHVE, right trisectionectomy with combined resection of the vena cava was performed.

Results. The operation time was $311 \mathrm{~min}$, and the blood loss was $420 \mathrm{ml}$. Pathological examination revealed complete resection of liver tumors, and the volumetry on postoperative day 7 revealed an increased remnant liver volume of $874 \mathrm{ml}$. He was discharged on postoperative day 10 without any complications.

Conclusion. Simultaneous DHVE could be an effective procedure to increase FLR with safety for massive hepatectomy.

DISCLOSURE The authors declare no conflict of interest.

\section{REFERENCES}

1. Kobayashi K, Yamaguchi T, Denys A, et al. Liver venous deprivation compared to portal vein embolization to induce hypertrophy of the future liver remnant before major hepatectomy: A single center experience. Surgery. 2020;167(6):917-23.

2. Heil J, Schadde E. Simultaneous portal and hepatic vein embolization before major liver resection. Langenbecks Arch Surg. 2020. https://doi.org/10.1007/s00423-020-01960-6.

3. Narita M, Oussoultzoglou E, Ikai I, Bachellier P, Jaeck D. Right portal vein ligation combined with in situ splitting induces rapid left lateral liver lobe hypertrophy enabling 2 -staged extended right hepatic resection in small-for-size settings. Ann Surg. 2012;256(3):e7-8 (Author reply e16-17).

4. Chan KS, Low JK, Shelat VG. Associated liver partition and portal vein ligation for staged hepatectomy: A review. Transl Gastroenterol Hepatol. 2020;5:37.

Publisher's Note Springer Nature remains neutral with regard to jurisdictional claims in published maps and institutional affiliations. 